\title{
Caso Atípico de Herpes Zoster Recorrente em Paciente Imunocompetente: Abordagem, Diagnóstico e Tratamento
}

\author{
Ana Cristina Diniz Silva \\ Médica perita, Tribunal de Justiça de Minas Gerais, Brasil; Mestre em Dermatologia/Master in Dermatology, University of \\ Hertfordshire, Reino Unido
}

RESUMO - Herpes zoster é uma doença infecciosa causada pela reativação do vírus varicela zoster nos gânglios sensoriais dorsais ou cranianos, caracterizada por erupções cutâneas vesiculares agrupadas que envolvem um ou mais dermátomos. É mais comum em idosos, eventualmente relacionado com o declínio da imunidade celular com a idade. Em adultos jovens, o herpes zoster correlaciona-se com frequência com condições clínicas de baixa imunidade. Esse artigo aborda um caso clínico de herpes zoster com apresentação atípica, tanto no que diz respeito à localização quanto ao elevado número de recorrências, em adulta jovem imunocompetente. O objetivo é discutir o caso, com base na evidência científica atual, enfatizando-se a sintomatologia, apresentação clínica, diagnóstico diferencial, impacto na qualidade de vida, conduta e tratamento.

PALAVRAS-CHAVE - Herpes Zoster; Herpes Simples; Herpesvirus Humano 3; Imunocompetência; Neuralgia Pós-Herpética; Vacina contra Herpes Zoster.

\section{Atypical Case of Recurrent Herpes Zoster in an Immunocompetent Patient: Assessment, Diagnosis and Management}

\begin{abstract}
Herpes zoster is an infectious disease caused by the reactivation of the varicella zoster virus in the cranial or dorsal sensorial ganglia, characterized by a vesicular skin rash affecting one or more dermatomes. It is more common in the elderly, in association with the decline of the cell-mediated immunity in advanced age. In young adults, herpes zoster infection correlates more frequently with clinical conditions of low immunity. This paper reports a clinical case of herpes zoster with an atypical presentation, both with regard to the location and the high number of recurrences in a young immunocompetent female patient. The author discusses the case, based on the current scientific evidence, emphasizing the symptoms, clinical presentation, differential diagnosis, impact on quality of life and management.
\end{abstract}

KEY-WORDS - Herpes Simplex; Herpes Zoster; Herpes Zoster Vaccine; Herpesvirus 3, Human; Immunocompetence; Neuralgia, Postherpetic.

\section{INTRODUÇ̃̃O}

Herpes zoster (HZ) é uma doença infecciosa caracterizada por erupções cutâneas vesiculares agrupadas que envolvem um ou mais dermátomos. Essa infecção é causada pelo vírus varicela zoster (VZV), o mesmo agente etiológico da varicela, mais comumente na infância. ${ }^{1}$ Após a resolução clínica da infecção primária, partículas virais ou pró-vírus migram pelos troncos nervosos e fixam-se nos gânglios sensitivos na espinal medula ou nos nervos cranianos. ${ }^{2}$
Uma vez alojado nos gânglios nervosos, essas partículas remanescentes ficam protegidas contra os altos níveis de anticorpos circulantes produzidos em resposta à infecção primária, os quais são responsáveis pela neutralização do vírus em ambiente extracelular. ${ }^{3}$ Latente nos gânglios, VZV mantem a capacidade de se reativar e multiplicar quando a imunidade celular baixa a níveis críticos. ${ }^{2} \mathrm{~A}$ imunidade mediada por células $T$ é o principal componente da resposta imunológica ao vírus, sendo necessária na eliminação das
Correspondência: Ana Cristina Diniz Silva Rua Euclides da Cunha, 261 - Cidade Nobre CEP 35162-364 - Ipatinga, MG - Brasil

E-mail: anacristina@sernobre.com.br
Recebido/Received

17 Junho/17 June 2016

Aceite/Accepted

12 Outubro/12 October 2016 


\section{Caso Clínico}

partículas intracelulares. ${ }^{3}$ Por isso, tanto a varicela quanto o $\mathrm{HZ}$ apresentam-se de forma mais grave em pacientes com imunodeficiência celular, particularmente em idosos. Além disso, tal história natural explica porque as lesões do $\mathrm{HZ}$ apresentam distribuição dermatomal. ${ }^{2}$

O risco de desenvolver $\mathrm{HZ}$ na população em geral é de aproximadamente $30 \%$, e aumenta de forma significativa a partir dos 50 anos de idade, 1 mas há casos descritos nos primeiros meses de vida. ${ }^{2} \mathrm{Um}$ estudo populacional recente, com 690 mil participantes, revelou uma idade média de 62 anos para a ocorrência da doença. Em adultos jovens, a infecção por $\mathrm{HZ}$ tende a ser associada com condições clínicas que reduzem a imunidade, tais como artrite reumatoide, doença inflamatória intestinal, terapia imunossupressora e neoplasias malignas. ${ }^{4}$

A dor associada ao quadro clínico-dermatológico agudo causa ansiedade, afetando o sono e as atividades diárias dos pacientes. Após a remissão da fase aguda, o quadro álgico pode persistir por meses ou anos, caracterizando a neuralgia pós-herpética. Tal complicação, mais frequente em idosos, ocorre em 20 a 50\% dos pacientes, sendo de difícil tratamento e podendo resultar em depressão e má qualidade de vida. ${ }^{5}$

\section{CASO CLÍNICO}

Trata-se de paciente do sexo feminino, 44 anos de idade, atendida no ambulatório com queixa de erupções cutâneas na palma e dedos da mão direita, de caráter recorrente (até 6 vezes ao ano) desde há cerca de 20 anos, sempre precedidas por parestesias e hiperestesia na face ventral do antebraço, sem acometimento de outros segmentos corporais ou mucosas. História de varicela aos 17 anos de idade, sem outra doença inflamatória crónica ou exposição a fármacos imunomoduladores.

O exame de PCR (polymerase chain reaction) da secreção das vesículas realizado em 1991 foi positivo para DNA de VZV e sorologias para os vírus herpes simplex 1 e 2 (HSV1 e HSV2) foram negativas em duas ocasiões diferentes, durante episódios agudos. Tais achados falam a favor do diagnóstico de infecção recorrente por VZV. A frequência das recorrências e o quadro álgico associado têm reduzido sua qualidade de vida, prejudicando seu sono e causando depressão e ansiedade, pelo que a paciente solicita opções terapêuticas que possam resolver ou amenizar seus sintomas clínicos.

Ao exame físico, observam-se dois pequenos agrupamentos de vesículas, sobre fundo eritematoso, na mão direita: um deles é localizado na porção medial da superfície palmar e o segundo na porção lateral do polegar. Centralmente, também na superfície palmar, há diminuta mácula eritematosa residual/cicatricial de lesão antiga (Fig. 1).

Foram prescritos à paciente, nessa ocasião, valaciclovir oral $1 \mathrm{~g}$. de 8 em 8 horas por 7 dias, e paracetamol 500 mg com codeína $30 \mathrm{mg}$ de 8 em 8 horas até a melhora sintomática. Foi colhida nova amostra para sorologias para HSV1 e HSV2, que foram negativas, assim como a

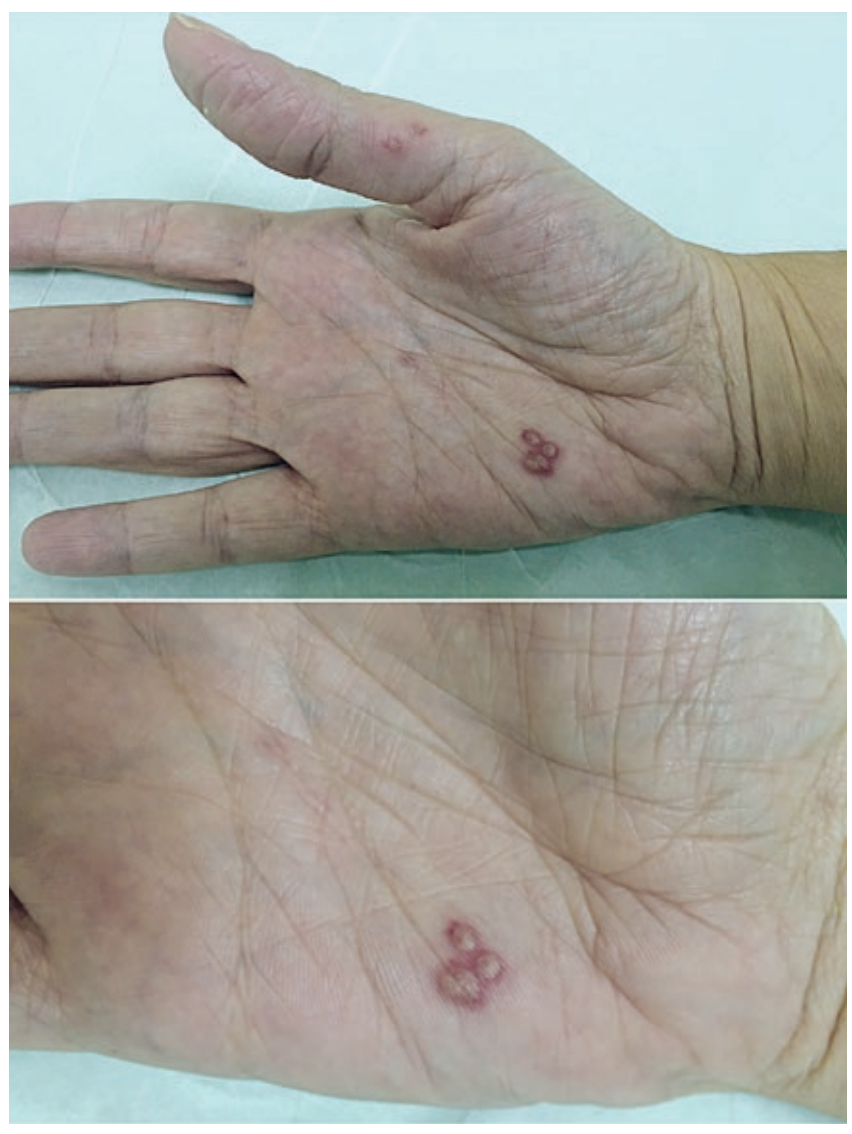

Figura 1 - Lesões vesiculares agrupadas na palma da mão e no polegar direito, em fundo eritematoso, com maior detalhe em (b). Na região palmar central, observa-se mácula eritematosa cicatricial.

sorologia para HIV. O restante estudo complementar que incluiu hemograma com plaquetas, imunoglobulinas séricas ( $\lg A, \lg E, \lg M, \lg G)$, células $C D 4+$ e $C D 8+$, eletroforese de proteínas, complemento e intradermo-reacção ao PPD também não revelou alterações.

Diante do diagnóstico clínico-laboratorial de $\mathrm{HZ}$ recorrente, a paciente foi orientada a receber uma dose da vacina para $\mathrm{HZ}$ (Zostavax ${ }^{\circledR}$ ) uma semana após o término da medicação, não tendo sido objectivada nenhuma outra recidiva desde então (espaço de 5 meses).

\section{DISCUSSÃO}

O contágio prévio pelo VZV, seja na forma de varicela ou pela vacinação, é o pré-requisito para a ocorrência de HZ. Nos EUA, mais de $90 \%$ da população adulta já teve varicela, o que aumenta o risco de desenvolver $\mathrm{HZ}{ }^{2}$

A associação entre a incidência de $\mathrm{HZ}$ e idades avançadas (> 50 anos) relaciona-se com o declínio da imunidade celular com a idade. ${ }^{2}$ São ainda fatores de risco a imunodeficiência, nomeadamente por infecção pelo vírus da imunodeficiência humana/síndrome da imunodeficiência adquirida, em indivíduos transplantados ou em tratamento com outros fármacos imunossupressores ou corticoterapia 
sistémica. ${ }^{2}$ Outros fatores têm sido associados ao aumento do risco de desenvolver HZ. Postula-se que o estresse emocional possa causar redução da imunidade mediada por células, resultando em "envelhecimento precoce" do sistema imunológico. Pesquisas também apontam que metais pesados, arsênico e pesticidas, bem como o uso abusivo de álcool e tabaco possam exercer ação imunossupressora. ${ }^{7}$

Trauma mecânico em determinados dermátomos poderão também precipitar $\mathrm{HZ}$, devido à reativação viral nas raízes nervosas dorsais por estímulo de nervos periféricos. Os achados de Thomas, et al mostram que história de trauma recente foi mais frequente entre os casos de $\mathrm{HZ}$ do que nos controles. ${ }^{7}$

Foi ainda investigado o papel de polimorfismos no gene da inter-leucina 10 na predisposição genética para $\mathrm{HZ}$, uma vez que essa citocina inibe a imunidade mediada por células. Resultados preliminares demonstraram que 53\% dos pacientes imunocompetentes que apresentaram episódio de $\mathrm{HZ}$ eram portadores do haplotipo ATA nesse gene, em comparação com apenas $38 \%$ dos controles. ${ }^{8}$

\section{EPIDEMIOLOGIA DO HZ RECORRENTE}

A incidência anual de $\mathrm{HZ}$ na população em geral é estimada em $1 \% .{ }^{6} \mathrm{~A}$ infecção recorrente é considerada rara, e a existência de mais do que um episódio recorrente, como no presente caso, é ainda mais rara. ${ }^{9-11}$ A taxa de ocorrência de um episódio recorrente em indivíduos que já apresentaram $\mathrm{HZ}$ varia de 1 a $6 \%$. $^{1}$ Considera-se que as recidivas afetem mais frequentemente indivíduos imunodeprimidos. No entanto, num estudo prospectivo conduzido por Nakamura et al, não foram observadas diferenças estatisticamente significativas na incidência de $\mathrm{HZ}$ recorrente entre as populações masculina e feminina, nem entre indivíduos imunocompetentes e imunossuprimidos. ${ }^{6}$

Os critérios diagnósticos de $\mathrm{HZ}$ recorrente utilizados foram um episódio prévio de infecção por $\mathrm{HZ}$ juntamente com o diagnóstico de $\mathrm{HZ}$ durante o período do estudo, baseado na combinação dos sintomas da infecção com resultados positivos de PCR e exames sorológicos. De acordo com os resultados, pacientes de 50 a 79 anos com diagnóstico de $\mathrm{HZ}$ recorrente apresentaram quadro clínico menos grave do que pacientes na mesma faixa etária com infecção primária, no que diz respeito ao grau de acometimento cutâneo, quadro álgico e risco de desenvolver neuralgia pós-herpética. Esses achados podem ser atribuídos à reação imunológica mediada por células, mais intensa nos pacientes com $\mathrm{HZ}$ recorrente, em comparação com aqueles que apresentaram episódio primário. ${ }^{6}$

A estimulação da resposta imune celular ("boosting") do VZV foi demonstrada em mães de crianças com varicela, o que sugere que a exposição ao antígeno contribui para a manutenção da imunidade. ${ }^{9}$ Tal fato é evidenciado por estudos que revelaram que a incidência de $\mathrm{HZ}$ é menor em adultos que mantêm contato próximo com crianças, o que aumenta a exposição ao vírus, e portanto, a imunidade. 9,10

De forma contraditória, um estudo tipo coorte realizado em adultos de Minnesota revelou uma taxa de recorrência de $\mathrm{HZ}$ de 6,2\% em 8 anos de follow-up, um índice mais alto do que os demonstrados em outras pesquisas. " Isso indica que a infecção por $\mathrm{HZ}$ não será um episódio único durante a vida de alguns indivíduos, sugerindo que a infecção não confere imunidade de longa duração. Se o conceito da estimulação e manutenção da resposta imunológica por um episódio de $\mathrm{HZ}$ é verdadeiro, esperar-se-ia o aumento de recorrências com o passar do tempo, fato não verificado nesse estudo. Pelo contrário, observou-se uma tendência de diminuição da taxa de recorrência ao longo do tempo do estudo. Além disso, de acordo com o conceito do efeito "boosting", a vacinação contra varicela reduziria o contato de adultos com o VZV e com seu efeito imunizador, o que resultaria em um aumento temporal dos casos de HZ. Essa tendência de aumento da incidência de $\mathrm{HZ}$ em adultos, no entanto, não foi observada. ${ }^{11}$ Uma explicação plausível para esse fato consiste em uma possível predisposição genética para a infecção e recorrência de HZ, como já mencionado. Os autores concluíram que, considerando-se as altas taxas de infecção recorrente verificadas, a vacina contra $\mathrm{HZ}$ deveria ser oferecida também a indivíduos imunocompetentes com história de $\mathrm{HZ}$, objetivando-se à prevenção de recorrências e de suas complicações. ${ }^{11}$

\section{DIAGNÓSTICO E TRATAMENTO DE HZ RECOR- RENTE}

Considerando-se a apresentação clínica relatada, há que se pensar no diagnóstico de herpes simples (HS) recorrente pelo HSV1. Como em alguns casos o diagnóstico diferencial não pode ser feito clinicamente devido à semeIhança dos sinais e sintomas, a confirmação por estudos de virologia torna-se necessária. O exame laboratorial mais usado para esse fim é a PCR, ou reação em cadeia da polimerase com o primer GPHV-RU, ${ }^{12}$ realizada no conteúdo das vesículas ou em amostra colhida por zaragatoa das lesões cutâneas. Utilizando a PCR para identificação viral foi demonstrado que muitos casos de $\mathrm{HZ}$ são erroneamente diagnosticados clinicamente como HS, ainda que na grande maioria dos casos de lesões recorrentes o diagnóstico clínico de HS seja correto e confirmado pelos achados da $\mathrm{PCR}$. Como a infecção recidivante por $\mathrm{HZ}$ mimetiza o $\mathrm{HS}$ clinicamente, a PCR têm-se mostrado um exame complementar útil, rápido eficaz, e imprescindível no diagnóstico diferencial entre $\mathrm{HS}$ e $\mathrm{HZ}$ recidivante, ${ }^{12,13}$ como no presente caso.

Além de um exame de PCR positivo para VZV em 1991, outros fatores indicam essa mesma etiologia para o quadro recorrente apresentado pela paciente, seja a mesma apresentação clínica em todos os episódios, seja as sorologias negativas para HSV1 e HSV2 em três ocasiões.

O caso clínico descrito refere-se a uma paciente saudável, na ausência de imunodeficiência. Estima-se que a prevalência de imunodeficiência primária ou inata seja de 1 em 1200 pessoas. Já a imunodeficiência secundária ou adquirida tem sido observada com mais frequência, devido ao 
uso crescente de tratamentos anti-neoplásicos e de medicamentos imunossupressores, incluindo os biológicos. Alguns exames laboratoriais são úteis na prática clínica, uma vez que resultados alterados podem indicar deficiências imunológicas primárias ou adquiridas. ${ }^{14}$

Em 2015, foi publicado um grande artigo de revisão sobre o tratamento do $\mathrm{HZ} .{ }^{15} \mathrm{O}$ uso de fármacos anti-virais associadas a analgésicos melhora os sintomas agudos da infecção, bem como previne complicações. Valaciclovir e fanciclovir, além de possuírem posologia cômoda, reduzem a gravidade e a extensão das lesões cutâneas, diminuem a dor e aceleram o processo de cura. $\bigcirc$ paracetamol pode ser usado isoladamente ou em combinação com a codeína. Em casos de dor persistente e refratária, podem-se associar anti-depressivos tricíclicos, como a amitriptilina, gabapentina ou opióides mais potentes, como a oxicodona. ${ }^{15}$

\section{PREVENÇÃO DA RECORRÊNCIA DE HZ EM PA-} CIENTES PREDISPOSTOS

Há cerca de 10 anos, a prevenção do HZ e suas complicações têm sido feita com o uso de uma vacina composta por VZV vivos e atenuados (Zostavax ${ }^{\circledR}$, Merck \& Co., Inc, NJ, USA), licenciada em vários países, inclusive no Brasil. Foi demonstrado que essa vacina reduz substancialmente a incidência de $\mathrm{HZ}$ e neuralgia pós-herpética, levando à melhoria da qualidade de vida de idosos e diminuindo o impacto social da doença. ${ }^{10}$

A vacinação é recomendada para grupos de alto risco, incluindo idosos e indivíduos com imunossupressão leve, sendo contra-indicada em pacientes gravemente imunodeprimidos, uma vez que se trata de vacina viva. Como não há como predizer a ocorrência de $\mathrm{HZ}$, adultos jovens e saudáveis devem ser informados e orientados adequadamente a respeito dos sintomas e complicações da doença, a fim de se decidir pelo uso da vacina, em conjunto com o médico assistente. Salienta-se que a vacina não desencadeia proteção em massa, uma vez que não há contágio inter-individual. A proteção dura até 10 anos, porém diminui com o avançar da idade. ${ }^{15}$

Desde 2006, quando a vacina foi inicialmente aprovada, uma dúvida com a qual nos deparamos é: a vacinação é eficaz para prevenir episódios recorrentes de $\mathrm{HZ}$ em pacientes com história prévia da infecção? A Food and Drug Administration (FDA) norte-americana destacou, quando da regulamentação da vacina, que um episódio de infecção por $\mathrm{HZ}$ é suficiente para estimular a resposta imunológica ao vírus, o que tornaria improvável a recorrência da doença. ${ }^{16}$ Além disso, a efetividade da vacina para a prevenção de HZ recorrente não foi evidenciada em estudos clínicos, embora Yawn et al recomendem Zostavax ${ }^{\circledR}$ para indivíduos imunocompetentes com história de $\mathrm{HZ}$, objetivando-se à prevenção de recorrência e de suas complicações. ${ }^{11}$

Tseng et al compararam a incidência de $\mathrm{HZ}$ recorrente em adultos imunocompetentes com mais de 60 anos, divididos em grupos os quais foram ou não vacinados após episódio inicial da infecção. Foi observada uma menor incidência de recorrência no grupo vacinado. No entanto, devido à baixa incidência de recorrência em ambos os grupos $(0,99 \%$ nos vacinados vs $2,20 \%$ nos não-vacinados), a vantagem da vacinação com esse objetivo não pôde ser confirmada. De acordo com os autores, tanto a infecção primária quanto a vacina são capazes de estimular, na mesma intensidade, a imunidade celular contra o vírus, o que tornaria a vacinação pouco eficaz nesses casos. Obviamente, apesar do baixo risco de desenvolver $\mathrm{HZ}$ recorrente após um episódio inicial, a real necessidade e a correta indicação da vacina deve ser avaliada de forma individualizada, considerando-se os aspectos clínicos de cada paciente, bem como o custo, disponibilidade e efeitos colaterais da vacina. ${ }^{16}$

Em relação ao uso de medicamentos anti-virais como profilaxia nos casos de $\mathrm{HZ}$ recorrente, faltam estudos clínicos que demonstrem sua eficácia, indicações e efeitos adversos na população imunocompetente. Há, na literatura, resultados positivos do uso contínuo de aciclovir profilático em pacientes HIV positivos ${ }^{17}$ e em pacientes em terapia imunossupressora ou quimioterápica, ${ }^{18}$ mas não em indivíduos considerados saudáveis do ponto de vista imunológico.

\section{CONCLUSÃO}

A apresentação e discussão desse caso clínico levantam vários pontos críticos na abordagem e manuseio de pacientes infectados por $\mathrm{HZ}$. Em primeiro lugar, há que se considerar o grande impacto negativo dessa infecção na qualidade de vida dos acometidos, principalmente em idosos e imunodeprimidos, que tendem a apresentar quadros recorrentes e muitas vezes incapacitantes. Considero atípico e raro o caso aqui relatado, por se tratar de adulta jovem, imunocompetente, com infecção altamente recorrente, em localização não usual.

Essa paciente foi corretamente diagnosticada através de PCR, há vários anos atrás, uma vez que o diagnóstico diferencial entre HS e HZ baseado puramente nos achados clínicos pode ser difícil, especialmente nos casos de $\mathrm{HZ}$ recorrente. Apesar de não ter sido repetida a PCR nas lesões atuais, a negatividade da sorologia para HSV1 e 2 favorece a infecção por VZV. A localização é também atípica ou pouco frequente. A inervação sensorial medial das palmas das mãos é feita pelas porções terminais do nervo ulnar, o qual se origina das raízes dorsais dos segmentos C8 a T1; - restante da superfície palmar, bem como o polegar são inervados pelo nervo mediano, oriundo das raízes de C5 a T1. Conclui-se, portanto, que as partículas virais remanescentes dessa paciente localizam-se em um ou mais segmentos de C5 a T1.

A paciente foi devidamente orientada e encaminhada ao serviço de vacinação com indicação clara para receber a vacina Zostavax ${ }^{\circledR}$ em dose única, após a resolução do quadro agudo. Embora precoces, cinco meses após a vacinação os resultados observados são bastante encorajadores, uma vez que a paciente não apresentou recidivas nem sinais de neuralgia pós-herpética. 
Conflitos de interesse: Os autores declaram não possuir conflitos de interesse. Suporte financeiro: $O$ presente trabaIho não foi suportado por nenhum subsídio ou bolsa. Confidencialidade dos dados: Os autores declaram ter seguido os protocolos do seu centro de trabalho acerca da publicação dos dados de doentes. Protecção de pessoas e animais: Os autores declaram que os procedimentos seguidos estavam de acordo com os regulamentos estabelecidos pelos responsáveis da Comissão de Investigação Clínica e Ética e de acordo com a Declaração de Helsínquia da Associação Médica Mundial.

Conflicts of interest: The authors have no conflicts of interest to declare. Financing Support: This work has not received any contribution, grant or scholarship. Confidentiality of data: The authors declare that they have followed the protocols of their work center on the publication of data from patients. Protection of human and animal subjects: The authors declare that the procedures followed were in accordance with the regulations of the relevant clinical research ethics committee and with those of the Code of Ethics of the World Medical Association (Declaration of Helsinki).

\section{REFERÊNCIAS}

1. Kawai K, Gebremeskel B, Acosta C. Systematic review of incidence and complications of herpes zoster: towards a global perspective. BMJ Open. 2014; 4:e004833.

2. Weinberg J. Herpes zoster: Epidemiology, natural history, and common complications. J Am Acad Dermatol. 2007; 57:S130-S5.

3. Gershon AA, Gershon MD, Brever J, Levin MJ, Oaklander $A L$, et al. Advances in the understanding of the pathogenesis and epidemiology of herpes zoster. J Clin Virol. 2010; 48,S2-S7.

4. Forbes H, Bhaskaran K, Thomas S, Smeeth L, Clayton T, Langan S. Quantification of risk factors for herpes zoster: population based case-control study. BMJ. 2014; 348:g2911.

5. Bricout $H$, Haugh M, Olatunde $O$, Gil Prieto R. Herpes zoster-associated mortality in Europe: a systematic review. BMC Public Health. 2015; 15(1).

6. Nakamura Y, Miyagawa F, Okazaki A, Okuno Y, Mori Y, Iso $\mathrm{H}$ et al. Clinical and immunologic features of recurrent herpes zoster (HZ). J Am Acad Dermatol. 2016 (In press).

7. Thomas SL, Hall AJ. What does epidemiology tell us about risk factors for herpes zoster? Lancet Infect Dis. 2004; 4:26-33.
8. Haanpaa M, Nurmikko T, Hurme M. Polymorphism of the IL-10 gene is associated with susceptibility to herpes zoster. Scand J Infect Dis. 2002; 34:112-14.

9. Gupta R, Gupta P, Gupta S. Pathogenesis of Herpes Zoster: A Review. Pharma Innov J. 2015; 4:11-3.

10. Oxman MN, Levin M, Johnson GR, Schmader KE, Straus SE, Gelb LD, et al. A vaccine to prevent herpes zoster and postherpetic neuralgia in older adults. N Engl J Med. 2005; 352:2271-84.

11. Yawn BP, Wollan PC, Kurland MJ, Sauver JL, Saddier P. Herpes zoster recurrences more frequent than previously reported. Mayo Clinic Proc. 2011; 86:88-93.

12. Rubben A, Baron J, Grussendorf-Conen E. Routine detection of herpes simplex virus and varicella zoster virus by polymerase chain reaction reveals that initial herpes zoster is frequently misdiagnosed as herpes simplex. $\mathrm{Br}$ J Dermatol. 1997; 137:259-61.

13. Nahass G, Mandel M, Cook S, Fan W, Leonardi C. Detection of herpes simplex and varicella-zoster infection from cutaneous lesions in different clinical stages with the polymerase chain reaction. J Am Acad Dermatol. 1995; 32:730-3.

14. Bright PD, Rooney N, Virgo PF, Lock RJ, Johnston SL, Unsworth DJ. Laboratory clues to immunodeficiency; missed chances for early diagnosis? J Clin Pathol. 2015; 68:1-5.

15. Johnson R, Alvarez-Pasquin M, Bijl M, Franco E, Gaillat $J$, Clara $J$ et al. Herpes zoster epidemiology, management, and disease and economic burden in Europe: a multidisciplinary perspective. Ther Adv Vaccines. 2015; 3:109-20.

16. Tseng HF, Chi M, Smith N, Marcy SM, Sy LS, Jacobsen SJ. Herpes zoster vaccine and the incidence of recurrent herpes zoster in an immunocompetent elderly population. J Infect Dis. 2012; 206:190-6.

17. Barnabas RV, Baeten JM, Lingappa JR, Thomas KK, Hughes JP, Mugo NR et al. Acyclovir prophylaxis reduces the incidence of herpes zoster among HIV-infected individuals: Results of a randomized clinical trial. J Infect Dis. 2015; 213:551-5.

18. Aoki T, Nishiyama T, Imahashi N \& Kitamura K. Efficacy of continuous, daily, oral, ultra-low-dose $200 \mathrm{mg}$ acyclovir to prevent herpes zoster events among bortezomib-treated patients: A report from retrospective study. Jpn J Clin Oncol. 2011; 41:876-81. 